\title{
Role of Ultrasound in Diagnosis of Fetal Cardiac Anomalies
}

\author{
Medhat M. Refat, Hamada M. Khater, Abdulrahman H. Tantawy
}

Department of Radiodiagnosis, Faculty of Medicine Benha University, Egypt.

Correspondence to: Abdulrahman H. Tantawy, Department of Radiodiagnosis, Faculty of Medicine Benha University, Egypt.

Email:

abdelrahmanhashimtantawy @ gmail.com

Received: 15 June 2020

Accepted: 31 August 2021

\begin{abstract}
Background: Congenital cardiac disease is seen in 2-6.5 of 1000 live births and is a major cause of morbidity and mortality, with half of these cases being lethal or requiring surgical correction. Environmental, genetic, and chromosomal abnormalities are believed to be causes of congenital cardiac defects, with a higher incidence among infants with affected siblings or mother. Extra-cardiac abnormalities are associated with $25 \%$ of these cases, Aim and objectives: The aim of the present study is to assess the role of ultrasound in diagnosis of fetal cardiac anomalies, Subjects and methods: This was a cross sectional study that was conducted on 100 pregnant ladies between 18 and 40 weeks gestation dated by last menstrual period (LMP) referred to fetal echocardiography unit of radiology department of Kasr El Ainy from Benha university hospital and other private clinics with suspected cardiac anomalies by routine obstetric ultrasound, Results: the results that sensitivity of $\mathrm{U} / \mathrm{S}$ in detection of paediatric heart disease was $100 \%$, specificity was $96.1 \%$, PPV was $96 \%$, NPV was $100 \%$, accuracy was
\end{abstract} 98\% with area under ROC curve 0.99, Conclusion: Prenatal diagnoses of fetal cardiac anomalies made by morphological ultrasonography exhibited good sensitivity, specificity, prenatal to postnatal concordance, and diagnostic validity.

Keywords: Prenatal, ultrasonography, cardiac, echocardiography.

\section{Introduction}

Congenital heart disease (CHD) is the most common cause of major congenital anomalies, representing a major global health problem. Twenty-eight percent of all major congenital anomalies consist of heart defects and affects approximately 6-11 per 1000 newborns. About 20-30\% of these heart defects are severe, defined as being potentially life threatening and requiring surgery within the first year of life (1). 
Only $10 \%$ of CHD cases occur in pregnancies with identifiable risk factors, Approximately half of the cases of congenital heart disease have only minor consequences or can be corrected easily with surgery, yet $35 \%$ of infant deaths due to congenital malformations are related to cardiovascular anomalies. Hence, congenital heart disease remains an important issue in infant health. In addition, cardiovascular anomalies are strongly associated with other anomalies or chromosomal aberrations (2).

Because the etiology of congenital malformations of the cardiovascular system is still largely unknown, primary prevention is not yet possible. The main options available as methods of secondary prevention are prenatal detection and subsequent adjustment of the obstetric policy or termination of the pregnancy if a fatal anomaly is detected. Prenatal detection of specific types of CHD may reduce neonatal mortality and morbidity (3).

It allows for planning the delivery at a tertiary-care center ensuring optimal neonatal and pre surgical care.Furthermore, parents can consider termination of pregnancy in severe cases (4).

Ultrasound visualization and interpretation of the fetal four-chamber view at 16 to 24 weeks' gestational age have been advocated as an efficient and accurate screening test for prenatal detection of the majority of cardiac malformations. Accordingly, assessment of the four-chamber view has been incorporated into routine fetal ultrasound in many countries (4).

The aim of the present study is to assess the role of ultrasound in diagnosis of fetal cardiac anomalies.

\section{Patients and methods}

This cross-sectional study included 100 pregnant ladies between 18 and 40 weeks gestation dated by LMP. Cases were collected from Obstetrics and Gynecology Department of Kasr Al Ainy.

\section{Exclusion criteria:}

- Cases with any other associated medical disorders were excluded from the study.

- Cases of structural abnormalities including different fetal systems apart from fetal heart as well as cases of fetal growth restriction (IUGR) were excluded from our study.

- Cases of polyhydramnios or multiple gestations were excluded from the study. 
Written informed consent was taken before the start of the study, which is approved by Ethics Committee for Human Research of Benha faculty of medicine.

A full history was taken from all of them including age, parity and history of any associated medical disorders or drug intake. An abdominal ultrasound was done for all cases including Doppler ultrasound. Fetal biometry was done for all cases including measurements of bi parietal diameter (BPD), occipito frontal diameter, head circumference $\quad(\mathrm{HC}), \quad$ abdominal circumference (AC) and femur length (FL). Doppler study of umbilical and middle cerebral arteries and ductus venosus was performed.

The machine used was Voluson Pro 730 (General Electric Medical Systems, Waukesha, Wisconsin, USA) and SonoAce X8 (Samsung Medison medical systems, Chicago, USA). Complete standardized fetal echocardiogram was performed for all diabetic pregnant ladies for full structural assessment. The control group underwent just basic and extended basic fetal cardiac examination. Measurement of the end diastolic inter ventricular septal thickness and myocardial free walls in lateral subcostal view in some cases and apical or

basal four chamber view in other cases (depending on fetal position at the time of scan) just inferior to atrio ventricular valves was performed for all cases.

\section{Statistical analysis :}

All data were collected, tabulated and statistically analyzed using SPSS 20.0 for windows (SPSS Inc., Chicago, IL, USA 2011). Quantitative data were expressed as the mean $\pm \mathrm{SD} \&$ (minimum-maximum), and qualitative data were expressed as absolute frequencies (number) \& relative frequencies (percentage). Continuous data were checked for normality by using Shapiro Walk test. Independent samples Student's t-test was used to compare between two groups of normally distributed variables while Mann Whitney U test was used for non- normally distributed variables. Kruskall Wallius test was used to compare between more than two groups of nonnormally distributed variables. Percent of categorical variables were compared using Chi-square test. All tests were two sided. Pvalue $<0.05$ was considered statistically significant and $\mathrm{p}$-value $\geq 0.05$ was considered statistically insignificant (NS)

\section{Results}


This study included 50 cases and 50 controls; there is no significant difference between the studied groups as regard age or gestational age. Table 1

There is no significant difference between the studied groups as regard baseline ultrasound findings. Table 2

There is a high significant difference between the studied groups as regard cardiothoracic ratio and 4 chamber views while there is no significant difference between the studied groups as regard Blood type RH. Table 3

There is a high significant difference between cases and control as regard $\mathrm{L}$ vot, $\mathrm{R}$ vot, Situs and Ventricular septum thickness. Table 4
The ultrasound showed that Hypertrophic cardiomyopathy was $24 \%$, Isolated ASD $34 \%$ and VSD was $26 \%$ comparing to echo with 66\% Hypertrophic cardiomyopathy, $16 \%$ Isolated ASD, 14\%VSD and 4\% negative, with no significant difference between ultrasound and echo in diagnosis of congenital heart. Figure 1

Regarding the validity of UIS in detection of paediatric heart disease by ROC curve, the sensitivity of U/S in detection of paediatric heart disease was $100 \%$, specificity was $96.1 \%$, PPV was $96 \%$, NPV was $100 \%$, accuracy was $98 \%$ with area under ROC curve 0.99 (figure 2).

Table (1): Comparison between cases and control as regard baseline data:

\begin{tabular}{|c|c|c|c|c|c|c|}
\hline & \multicolumn{2}{|c|}{$\begin{array}{l}\text { Cases } \\
\mathrm{N}=50 \\
\end{array}$} & \multicolumn{2}{|c|}{$\begin{array}{c}\begin{array}{c}\text { Control } \\
\mathbf{N}=50\end{array} \\
\end{array}$} & T test & $P$ value \\
\hline $\begin{array}{c}\text { Age } \\
\text { mean } \pm \text { SD } \\
(\text { Range })\end{array}$ & \multicolumn{2}{|c|}{$\begin{array}{c}24.11 \pm 3.87 \\
\quad(19-32)\end{array}$} & \multicolumn{2}{|c|}{$\begin{array}{c}24.22 \pm 3.11 \\
\quad(18-32)\end{array}$} & 0.142 & 0.887 \\
\hline $\begin{array}{c}\text { Gestational age } \\
\text { mean } \pm \text { SD } \\
\text { (Range) }\end{array}$ & \multicolumn{2}{|c|}{$\begin{array}{c}26.31 \pm 2.77 \\
(19-30)\end{array}$} & \multicolumn{2}{|c|}{$\begin{array}{c}26.46 \pm 2.85 \\
\quad(19-30)\end{array}$} & 1.1 & 0.821 \\
\hline Gender & No. & $\%$ & No. & $\%$ & $X^{2}$ & $P$ value \\
\hline Male & 26 & 52.0 & 25 & 50.0 & 0.099 & 0.911 \\
\hline Female & 24 & 48.0 & 25 & 50.0 & & \\
\hline
\end{tabular}


Table (2): Comparison between cases and control as regard baseline ultrasound findings:

\begin{tabular}{|c|c|c|c|c|}
\hline & $\begin{array}{l}\text { Cases } \\
\mathbf{N}=\mathbf{5 0} \\
\end{array}$ & $\begin{array}{c}\begin{array}{c}\text { Control } \\
\mathbf{N}=\mathbf{5 0}\end{array} \\
\end{array}$ & $\mathbf{T}$ test & $P$ value \\
\hline $\begin{array}{c}\text { Head circumference } \\
\text { mean } \pm \text { SD } \\
(\text { Range })\end{array}$ & $\begin{array}{c}244.69 \pm 29.01 \\
\quad(161-273)\end{array}$ & $\begin{array}{c}245.66 \pm 29.3 \\
(162-274)\end{array}$ & 1.01 & 0.712 \\
\hline $\begin{array}{c}\text { Abd. Circumference } \\
\text { mean } \pm \text { SD } \\
(\text { Range })\end{array}$ & $\begin{array}{c}222.91 \pm 30.67 \\
(142-258)\end{array}$ & $\begin{array}{c}223.92 \pm 30.6 \\
(142-258)\end{array}$ & 0.891 & 0.832 \\
\hline $\begin{array}{c}\text { Femur length } \\
\text { mean } \pm \text { SD } \\
\text { (Range) }\end{array}$ & $\begin{array}{c}49.30 \pm 6.29 \\
(30-59)\end{array}$ & $\begin{array}{c}49.45 \pm 6.81 \\
\quad(30-59)\end{array}$ & 1.02 & 0.711 \\
\hline $\begin{array}{c}\text { Bi-parietal diameter } \\
\text { mean } \pm S D \\
(\text { Range })\end{array}$ & $\begin{array}{c}66.32 \pm 7.11 \\
(46-77)\end{array}$ & $\begin{array}{c}66.99 \pm 7.78 \\
(46-77)\end{array}$ & 0.941 & 0.703 \\
\hline $\begin{array}{c}\text { Amniotic fluid index } \\
\text { mean } \pm \text { SD } \\
\text { (Range) }\end{array}$ & $\begin{array}{c}11.38 \pm 0.77 \\
(10-12)\end{array}$ & $\begin{array}{c}11.98 \pm 0.79 \\
(10-14)\end{array}$ & 0.899 & 0.891 \\
\hline
\end{tabular}

Table (3): Comparison between cases and control as regard Blood type RH, Cardio-thoracic ratio and4 chamber view:

\begin{tabular}{|c|c|c|c|c|c|c|}
\hline & \multicolumn{2}{|c|}{$\begin{array}{l}\text { Cases } \\
\mathrm{N}=50\end{array}$} & \multicolumn{2}{|c|}{$\begin{array}{c}\text { Control } \\
\mathbf{N}=\mathbf{5 0}\end{array}$} & \multirow[t]{2}{*}{$X^{2}$} & \multirow[t]{2}{*}{$P$ value } \\
\hline & No. & $\%$ & No. & $\%$ & & \\
\hline Blood type RH & & & & & 0.078 & 0.77 \\
\hline Positive & 42 & 84.0 & 43 & 86.0 & & \\
\hline Negative & 8 & 16.0 & 7 & 14.0 & & \\
\hline Cardio-thoracic ratio & & & & & Fisher test & $<0.001$ \\
\hline Normal & 1 & 2.0 & 50 & 100.0 & & (HS) \\
\hline Abnormal & 49 & 98.0 & 0 & 0.0 & & \\
\hline 4 chamber view & & & & & Fisher test & $<0.001$ \\
\hline Normal & 2 & 4.0 & 50 & 100.0 & & $(\mathbf{H S})$ \\
\hline Abnormal & 48 & 96.0 & 0 & 0.0 & & \\
\hline
\end{tabular}

Table (4): Comparison between cases and control as regard L vot, R vot, Situs and Ventricular septum thickness:

\begin{tabular}{|c|c|c|c|c|c|c|}
\hline & \multicolumn{2}{|c|}{$\begin{array}{l}\text { Cases } \\
\mathbf{N}=50\end{array}$} & \multicolumn{2}{|c|}{ 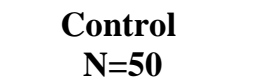 } & \multirow[t]{2}{*}{$X^{2}$} & \multirow[t]{2}{*}{$P$ value } \\
\hline & No. & $\%$ & No. & $\%$ & & \\
\hline L vot & & & & & Fisher & $<0.001$ \\
\hline Normal & 4 & 8.0 & 50 & 100.0 & test & $(\mathbf{H S})$ \\
\hline Abnormal & 46 & 92.0 & 0 & 0.0 & & \\
\hline $\mathbf{R}$ vot & & & & & Fisher & $<0.001$ \\
\hline Normal & 2 & 4.0 & 50 & 100.0 & test & (HS) \\
\hline Abnormal & 48 & 96.0 & 0 & 0.0 & & \\
\hline Situ & & & & & Fisher & $<0.001$ \\
\hline Normal & 1 & 2.0 & 50 & 100.0 & test & $(\mathbf{H S})$ \\
\hline Abnormal & 49 & 98.0 & 0 & 0.0 & & \\
\hline Ventricular septum thickness & & & & & Fisher & $<0.001$ \\
\hline Normal & 0 & 0.0 & 50 & 100.0 & test & (HS) \\
\hline Abnormal & 50 & 100.0 & 0 & 0.0 & & \\
\hline
\end{tabular}




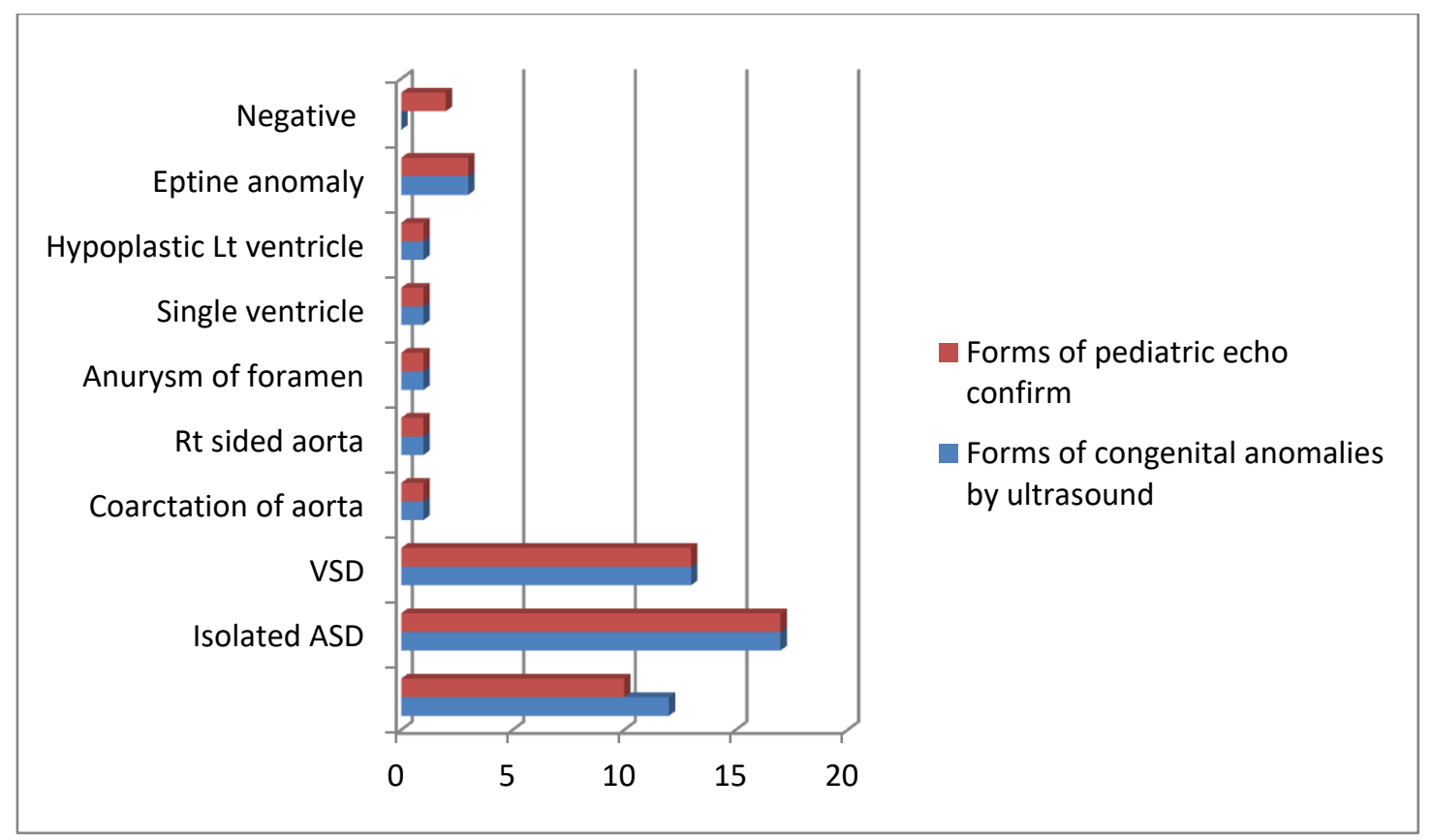

Fig.(1) Comparison between ultrasound and echo as regard Characteristics of the studied Congenital heart cases

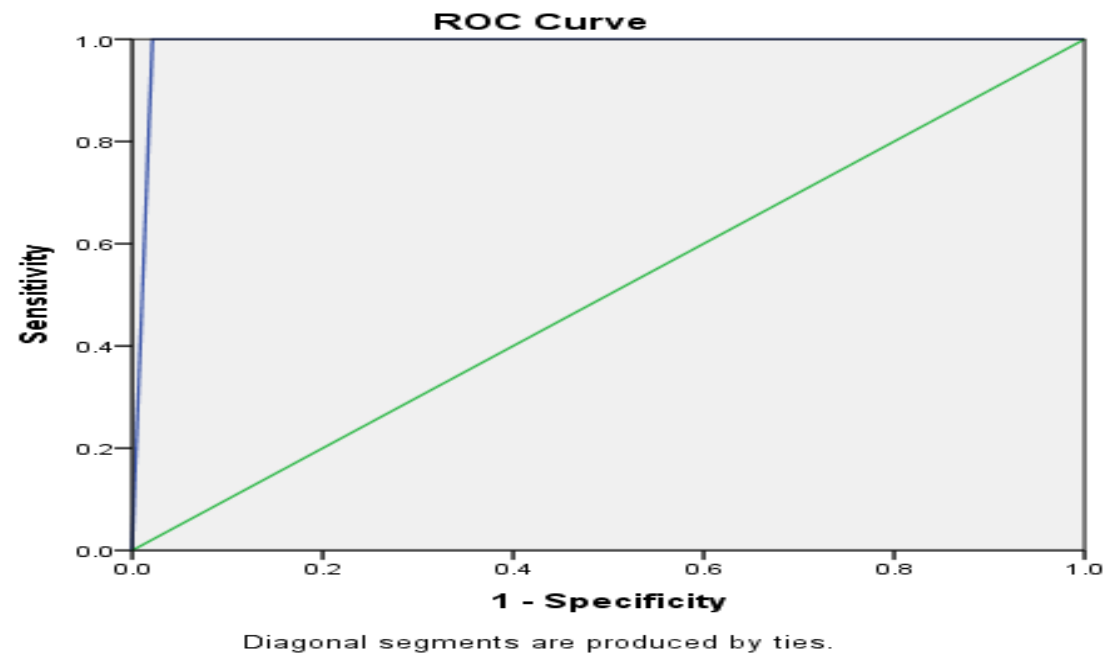

Fig. (2): ROC curve for UlS in detection of paediatric heart disease

\section{Discussion}

The present study compared between the participants case and control groups regarding baseline ultrasonic data and revealed that there is no significant difference between the studied groups as regard baseline ultrasound findings where Head circumference was with mean of 244.69 \pm 29.01 , Abdominal Circumference with a mean \pm SD of $222.91 \pm 30.67$ while Femur length with a mean \pm SD of 
49.30 \pm 6.29 , Bi-parietal diameter with mean $\pm \mathrm{SD}$ of $66.32 \pm 7.11$ and Amniotic fluid index with mean $\pm \mathrm{SD}$ is $11.38 \pm 0.77$ among case group.

In agreement with our results, the study of Ruiz et al., (5) that aimed to determine the longitudinal behavior of fetal biometric measures and cerebro-placental hemodynamics throughout gestation in fetuses with congenital heart disease (CHD), the following biometrics were present among case group :BPD (mm) was $58.1 \pm$ 12.0, HC (mm) was $210.7 \pm 43.1$, abdominal circumference was $(\mathrm{mm}) \quad 193.8 \pm 45.8$, FL $(\mathrm{mm}) 41.9 \pm 10.7$, and there was no statistical significant different between groups as regard baseline biometric measures.

The present study revealed that there is high significant difference between the studied groups as regard cardio-thoracic ratio and 4 chamber views while there is no significant difference between the studied groups as regard Blood type $\mathrm{RH}$.

In the study done 1990 (6), the cardiothoracic ratio was measured in 410 normal fetuses and in a group of 73 fetuses with functional or structural heart disease. In normal fetuses it was fairly constant throughout pregnancy, but of those with congenital heart disease it was raised in cases of Ebstein's anomaly, tricuspid dysplasia, atrioventricular septal defect, and complete heart block. In some forms of congenital heart disease, however, it was within the normal range. There was a significant positive correlation between the cardiothoracic ratio and fetal hydrops in the group of 15 fetuses with supraventricular tachycardias. In these fetuses the cardiac size decreased significantly once the fetus reverted to sinus rhythm after the mother had been treated.

Congenital heart disease (CHD) is a common anomaly in newborns. Improvements in the antenatal diagnosis of cardiac anomalies have resulted in a significant reduction in neonatal morbidity and mortality. With early diagnosis, good intra-natal and postnatal care can be offered to a baby with a cardiac anomaly and the family can be prepared emotionally and financially to accept such a baby (7).

The present study revealed that there is high significant difference between cases and control as regard L vot, $\mathrm{R}$ vot, and Situs and Ventricular septum thickness. 
Early screening of fetal CHD is vital for perinatal period health care and improving the prognosis of neonatal; furthermore, it can also promote the rapid development of fetal CHD treatment technology. What is more, earlier screening of fetal CHD can provide parents an opportunity to a safe termination of pregnancy or make a choice to karyotype analysis or genetic counseling. For parents who are at risk for having a CHD child, the finding of normal cardiac anatomy can relieve their anxious during early-stage per pregnancy (8).

The present study revealed that ultrasound can detect $24 \%$ of Hypertrophic cardiomyopathy, Isolated ASD 34\% and VSD was $26 \%$ comparing to $66 \%$ Hypertrophic cardiomyopathy, 16\% Isolated ASD, $14 \%$ VSD and 4\% negative with no significant difference between ultrasound and echo in diagnosis of congenital heart, in another study of Rocha et al., (9) that aimed to describe the experience of a tertiary center in Brazil to which patients are referred whose fetuses are at increased risk for congenital heart diseases (CHDs) in which they identified $48.1 \%$ complex cases, $18.5 \%$ significant cases, $7.4 \%$ minor cardiac anomalies, and $26 \%$ were others. Others cases were dysrhythmia (complete atrioventricular dissociation), hypertrophy myocardial, dextroposition secondary, and ductus arteriosus restrictive.

In a study carried out in 2019 (10) the sensitivity of $97.7 \%$, a specificity of $88.9 \%$, and an accuracy of $93.0 \%$ in the diagnosis of congenital cardiomyopathy during the prenatal period. Ninety-six percent of the pregnant women of the study underwent at least one obstetric echography, but only $36.5 \%$ underwent a morphological echography. While analyzing each type of echography separately, they found a sensitivity of $29.3 \%$ for the obstetric echography, of $97.7 \%$ for the morphologic echography, and of $97.7 \%$ for the fetal echocardiography $(p<0.05)$.

In Friedberg et al., (11), series, prenatal detection of d-transposition of the great arteries (19\%), total anomalous pulmonary venous return $(0 \%)$, and tetralogy of Fallot $(31 \%)$ was relatively low, whereas that of hypoplastic left heart syndrome $(61 \%)$, other single ventricles (64\%), atrioventricular canal defect (50\%), and complex heterotaxy $(82 \%)$ was relatively high. The authors go on to describe the overall inconsistency with which abnormalities of the ventricular outflow tracts were identified and/or reported. One could infer from these findings that many of the undiagnosed cases 
of CHD could be explained by the ultrasound provider's relative lack of familiarity with techniques for assessing the ventricular outflow tracts by ultrasound or limited fund of knowledge regarding normal and abnormal outflow tract anatomy.

In the present we assessed the validity of ultrasound in detection of congenital heart disease and revealed that sensitivity of U/S in detection of paediatric heart disease was $100 \%$, specificity was $96.1 \%$, PPV was $96 \%$, NPV was $100 \%$, and accuracy was $98 \%$ with area under ROC curve 0.99 .

A retrospective study done in 2000 (12) in America with expectant mothers who underwent morphological ultrasound scans at between 15 and 26 weeks, found sensitivity and specificity of $71 \%$ and $99 \%$, respectively. Another retrospective study carried out later on 2004 (13), which assessed the effectiveness of prenatal ultrasonography for detecting congenital anomalies, reported specificity of $99.9 \%$. Although our study differed from some other published research by setting the lower limit of gestational age for morphological ultrasonography at the $18^{\text {th }}$ week, prenatal diagnosis of fetal anomalies achieved a sensitivity of $100 \%$ and a specificity of $96.1 \%$. Another point that should be made clear is that our study recruited a smaller number of patients $(n=50)$ when compared with other recent studies, which may explain the differences observed between the diagnostic validation figures.

The divergent results in the studies mentioned above are primarily the result of the study populations and the degree of specialization of the ultrasound professionals. While some of the studies are population-based, i.e. they cover all expectant mothers in a given period, others are carried out at a hospital level, including pregnancies at high-risk of congenital anomalies. One issue worthy of note is that some of these studies were carried out in maternity units with a primary level of complexity, and make unsatisfactory reference to high-risk patients.

On the other hand, the present study revealed that sensitivity of U/S in detection of paediatric hypertrophic cardiomyopathy was $100 \%$, specificity was $97.7 \%$, PPV was $83.3 \%$, NPV was $100 \%$ and accuracy was 98\%, while in another study done in 2015 (14) in which ROC curves were constructed for estimating the association between the prenatal IVS thickness, RMWT, and LMWT and the postnatal diagnosis of HCM. All of these measurements showed significant 
predictability, with the prenatal IVS thickness being the most predictable, having the largest area under the curve. A prenatal IVS thickness of $\geq 4.5 \mathrm{~mm}$ was associated with a postnatal diagnosis of $\mathrm{HCM}$ at a sensitivity of $82 \%$, a specificity of $68 \%$, a positive predictive value (PPV) of $37 \%$, a negative predictive value (NPV) of $94 \%$, a positive likelihood ratio $(\mathrm{LR}+)$ of 2.6 , and an overall accuracy of $72 \%$.

In the sonographic prenatal diagnosis of CHD, the fetal heart remains a challenge that involves sonographers, obstetricians, radiologists, and fetal medicine subspecialists. High risk for cardiac defects and the suspicion of a cardiac abnormality on obstetric ultrasound, even in low-risk populations, are indications for referral for performance of a detailed fetal echocardiogram (15).

Intra-cardiac shunt malformations are the most common congenital cardiac defects leading to left-right shunt after birth. Atrial, ventricular, and atrioventricular septal defects are included in this group. These defects can be associated with other cardiac malformations and, depending on their magnitude, are responsible for heart failure postnatally, however with no hemodynamic significance during fetal life (15).
Additionally, the present study revealed that sensitivity of U/S in detection of paediatric isolated ASD and VSD was $100 \%$, specificity was $100 \%$, PPV was $100 \%$, NPV was $100 \%$ and accuracy was $100 \%$, also we revealed that sensitivity of U/S in detection of paediatric other cardiac anomalies was $100 \%$, specificity was $100 \%$, PPV was $100 \%$, NPV was $100 \%$ and accuracy was $100 \%$.

A recent retrospective cohort study done in 2019 (10) with 96 pregnant women who were attended at the Echocardiography Service and whose deliveries occurred at the Complexo Hospitalar Santa Casa de Porto Alegre, in the state of Rio Grande do Sul, Brazil, Risk factor assessment plus sensitivity and specificity analysis were used, comparing the accuracy of the screening for congenital heart disease by means of obstetrical ultrasound and morphological evaluation and fetal echocardiography, the results revealed that The analysis of risk factors shows that $31.3 \%$ of the fetuses with congenital heart disease could be identified by anamnesis. The antepartum echocardiography demonstrated a sensitivity of $97.7 \%$, a specificity of $88.9 \%$, and accuracy of $93 \%$ in the diagnosis of congenital heart disease. A sensitivity of $29.3 \%$ was found for the 
obstetric ultrasound, of $54.3 \%$ for the morphological ultrasound, and of $97.7 \%$ for the fetal echocardiography. The fetal echocardiography detected fetal heart disease in $67.7 \%$ of the cases, the morphological ultrasound in $16.7 \%$, and the obstetric ultrasound in $11.5 \%$ of the cases.

Despite the recommendation of the American Institute of Ultrasound in Medicine (16) for sonographic cardiac screening examination including fourchamber view, left and right ventricular outflow tracts, the report of the sonographic examination should also document the nature of eventual technical limitations, such as increased maternal abdominal wall thickness. We are not sure how the sonographic cardiac screening examination was performed, if it included in fact fourchamber view and ventricular outflow tracts. In general, obstetric echography has a summarized description of the ultrasound report. This data is important because it actually expresses the real way how the description of the sonographic cardiac screening is obtained in the majority of the obstetric exams in the daily assistance, which, in spite of its evolution in the last decade, it is still far from the ideal.
The detection rates of cardiomyopathies in routine obstetric exams are low. However, fetal echocardiography is a sensitive and specific tool for the detection of these pathologies. Based on these findings, we stress the importance of a detailed fetal morphological exam in an audited service, with properly trained echographists enabled to ratify the fetal echocardiography whenever facing an unsatisfactory exam during the prenatal evaluation, in order to facilitate the optimization in the rate detection of congenital fetal cardiomyopathies, enabling the handling of these cases.

The fetal echocardiography screening can be used in the evaluation of low-risk fetuses examined as part of the routine prenatal care, enabling a more accurate diagnosis of cardiac defects. Knowing that the risk of cardiomyopathy of the population in general is of $\sim 1 \%$, there would be an indication for fetal echocardiography, considering the favorable cost-benefit, in all situations when the absolute risk is higher than this amount, according to the following subdivision: high risk when the absolute risk is estimated > $2 \%$, low risk when the absolute risk is estimated between 1 and 2\%, and absence of risk when the absolute risk is $<1 \%$, without 
indication for fetal echocardiography in the last case (17).

In addition, according to updated guidelines, a fetal echocardiogram should be performed if congenital heart defect is suspected, if the normal four-chamber and outflow tract views cannot be obtained at the time of screening, or if recognized risk factors indicate an increased risk of congenital cardiac anomalies (18).

\section{Conclusion}

Prenatal diagnoses of fetal cardiac anomalies made by morphological ultrasonography exhibited good sensitivity, specificity, prenatal to postnatal concordance, and diagnostic validity

\section{References}

1. Dolk H, Loane M, Garne E. The prevalence of congenital anomalies in Europe. Adv Exp Med Biol. 2010;686:349-64.

2. Levy DJ, Pretorius DH, Rothman A, Gonzales M, Rao C, Nunes ME, et al. Improved prenatal detection of congenital heart disease in an integrated health care system. Pediatr Cardiol. 2013;34(3):670-9.

3. Schwedler G, Lindinger A, Lange PE, Sax U, Olchvary J, Peters B, et al. Frequency and spectrum of congenital heart defects among live births in Germany. Clin Res Cardiol. 2011;100(12):1111-7.
4. Van Velzen CL, Clur SA, Rijlaarsdam MEB, Bax CJ, Pajkrt E, Heymans MW, et al. Prenatal detection of congenital heart disease-results of a national screening programme. BJOG An Int J Obstet Gynaecol. 2016;123(3):400-7.

5. Ruiz A, Cruz-Lemini M, Masoller N, SanzCortés M, Ferrer Q, Ribera I, et al. Longitudinal changes in fetal biometry and cerebroplacental hemodynamics in fetuses with congenital heart disease. Ultrasound Obstet Gynecol. 2017;49(3):379-86.

6. Paladini D, Chita SK, Allan LD. Prenatal measurement of cardiothoracic ratio in evaluation of heart disease. Arch Dis Child. 1990;65(1 Spec No):20-3.

7. Espinoza J, Kusanovic JP, Gonçalves LF, Nien JK, Hassan S, Lee W, et al. A novel algorithm for comprehensive fetal echocardiography using 4-dimensional ultrasonography and tomographic imaging. $\mathbf{J}$ ultrasound Med. 2006;25(8):947-56.

8. Hartge DR, Weichert J, Krapp M, Germer U, Gembruch U, Axt-Fliedner R. Results of early foetal echocardiography and cumulative detection rate of congenital heart disease. Cardiol Young. 2011;21(5):505-17.

9. Rocha LA, Araujo Júnior E, Rolo LC, Barros FSB, da Silva KP, Leslie ATFS, et al. Prenatal detection of congenital heart diseases: one-year survey performing a screening protocol in a single reference center in Brazil. Cardiol Res Pract. 2014; ;17(1):26-31.

10. Pinheiro DO, Varisco BB, da Silva MB, Duarte RS, Deliberali GD, Maia CR, et al. Accuracy of prenatal diagnosis of congenital cardiac 
malformations. Rev Bras Ginecol e Obs Gynecol Obstet. 2019;41(01):11-6.

11. Friedberg MK, Silverman NH, Moon-Grady AJ, Tong E, Nourse J, Sorenson B, et al. Prenatal detection of congenital heart disease. J Pediatr. 2009;155(3):29-35.

12. Bricker L, Garcia J, Henderson J, Mugford M, Neilson J, Roberts $\mathrm{T}$, et al. Ultrasound screening in pregnancy: a systematic review of the clinical effectiveness, cost-effectiveness and women's views. In: Database of Abstracts of Reviews of Effects (DARE): Quality-assessed Reviews [Internet]. Centre for Reviews and Dissemination (UK); 2000; 5: 76-81..

13. França LC, Murta CG V, Moron AF, Montenegro CAB. Reflexão sobre a ultrassonografia na Obstetrícia: como melhorar a qualidade. Femina. 2004;32:167-70.

14. Elmekkawi SF, Mansour GM, Elsafty MSE, Hassanin AS, Laban M, Elsayed HM. Prediction of fetal hypertrophic cardiomyopathy in diabetic pregnancies compared with postnatal outcome. Clin Med Insights Women's Heal. 2015;8:CMWH-S32825.
15. Bravo-valenzuela NJ, Peixoto AB, Júnior EA. Prenatal diagnosis of congenital heart disease: A review of current knowledge. Indian Heart $\mathbf{J}$. 2018;70(1):150-64.

16. Medicine AI of $\mathrm{U}$ in. AIUM practice guideline for the performance of obstetric ultrasound examinations. $\mathbf{J}$ ultrasound Med Off $\mathbf{J}$ Am Inst Ultrasound Med. 2010;29(1):157.

17. Donofrio MT, Moon-Grady AJ, Hornberger LK, Copel JA, Sklansky MS, Abuhamad A, et al. American Heart Association Adults With Congenital Heart Disease Joint Committee of the Council on Cardiovascular Disease in the Young and Council on Clinical Cardiology, Council on Cardiovascular Surgery and Anesthesia, and Council on Cardiovascular and S. Circulation. 2014;129(21):2183-242.

18. Carvalho JS, Allan LD, Chaoui R, Copel JA, DeVore GR, Hecher K, et al. ISUOG Practice Guidelines (updated): sonographic screening examination of the fetal heart. Ultrasound Obstet Gynecol. 2013;41(3):348-59.

To cite this article: Medhat M. Refat, Hamada M. Khater, Abdulrahman H. Tantawy. Role of Ultrasound in Diagnosis of Fetal Cardiac Anomalies. BMFJ 2022;39(Radiology):55-67. DOI: 10.21608/bmfj.2021.32798.1274 